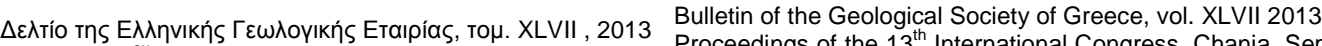

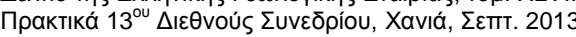
2013

\title{
QUANTITATIVE DETERMINATION OF MINERAL MATTER IN LIGNITE BY X-RAY SPECTROMETRY, USING THE COMPTON EFFECT
}

\author{
Perdikatsis V. \\ Technical University of Crete, Department of Mineral Resources Engineering, Chania, Greece, \\ vperdikatsis@isc.tuc.gr
}

\begin{abstract}
For the evaluation of lignite quality, apart from the calorific value, it is necessary to determine the mineral phases, which are deposited simultaneously with the organic matter during the formation of peat or formed epigenetically during the coalification stages.

The mineral matter content is usually expressed as ash, after the combustion of lignite, and its determination is a quite time consuming process.

In this paper an attempt is made for a fast and easy quantitative determination of mineral matter in lignite samples with unknown concentrations, with the use of an $X$-ray spectrometer and in particular the Compton effect of the X-ray tube.

The intensity of the Compton peak is a function of the mass absorption coefficient of the lignite sample, which in turn depends on the type and amount of the mineral matter contained.

Using this property of the Compton Effect, the percentage of mineral matter of lignite was determined. The method was verified by analyzing lignites with known concentrations of inorganic mater.

The results of this study showed, that the mineral matter content can be determined, by the proposed method, fast and accurately without lignite combustion.

Key words: Lignite, mineral matter, XRF, Compton Scattering.
\end{abstract}

\section{Пєрí $\eta \psi \eta$}

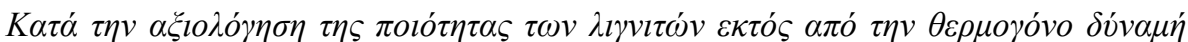

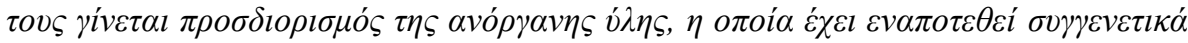

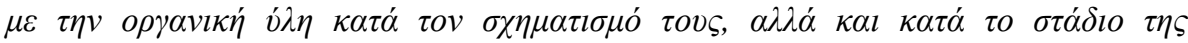

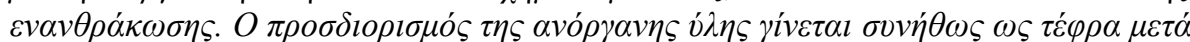

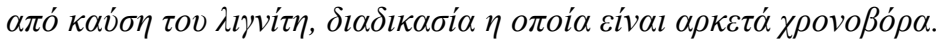

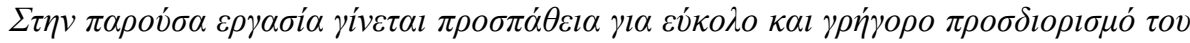

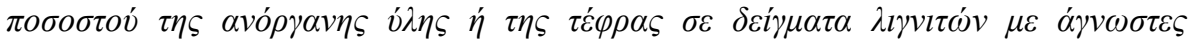

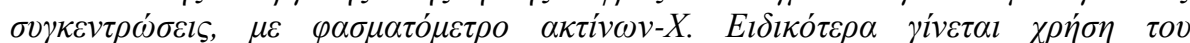

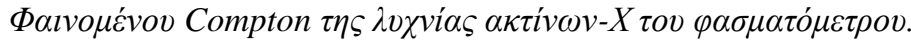

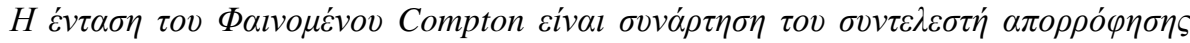

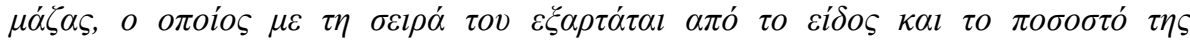

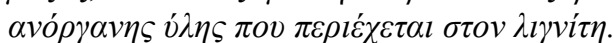

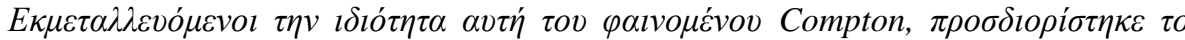

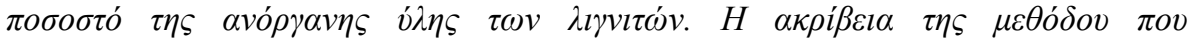

$\underline{\text { XLVII, No } 3-1645}$ 


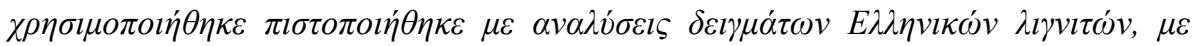

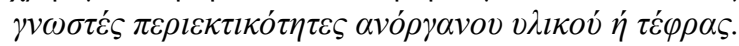

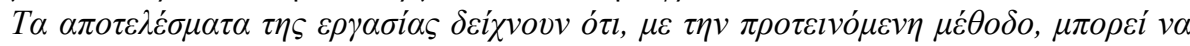

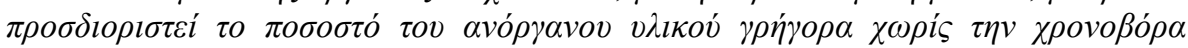

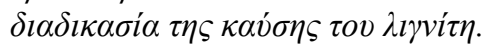

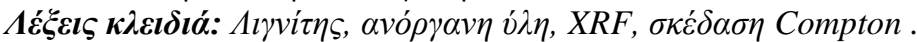

\title{
1. Introduction
}

The quality of lignite, apart from the calorific value, depends strongly on the mineral matter, which is deposited simultaneously with the organic matter during the peat forming stage, but also epigenetically during the coalification stages. The mineral matter content is fundamental for the evaluation of coal quality for a variety of applications. The content of the mineral matter can also be used to evaluate the behavior of particular coals in utilization processes, including the processes that control the characteristics of fly ashes, slags and other combustion by-products.

"Mineral matter" is defined by Gary et al. (1972) as "the inorganic material in coal". More specifically is defined by Australian Standards (2000) as "the sum of the minerals and inorganic matter in and associated with coal". Similar definitions are provided by Harvey and Ruch (1986) and by Finkelman (1994).

The most common method for the determination of mineral matter content is the combustion of lignite, expressed as ash (ASTM 3174), a process which is quite time consuming. In Low Temperature Ashing (LTA) the organic matter is destroyed by an electronically-excited oxygen plasma at temperature of around $120^{\circ} \mathrm{C}$ (Gluskoter, 1965). The oxygen is excited to ozone, which is passed around the sample and removes completely the organic matter. By LTA all the minerals of the inorganic matter are preserved more or less in their original state, which is very important, especially for the clay minerals, gypsum, sulfides, etc.

A comparative study of the different methods for the determination of mineral matter is given by Colin R. Ward (2002). Ritz and Klika (2010) determined mineral matter by recalculation of the bulk chemical analysis of lignite. Tickner and Roach (2004) determined the mineral matter content by a Compton profile analysis via XRF (X-ray Fluorescence). The apparatus used for the coal measurements comprised a $300 \mathrm{mCi}(11.1 \mathrm{GBq}){ }^{241} \mathrm{Am}$ source (producing $59.54 \mathrm{keV}$ gamma-rays, with a weaker component at $26.34 \mathrm{keV}$ ) and a $36 \cdot 10 \mathrm{~mm}$ germanium detector.

In the present paper the mineral matter content was determined using the Compton Peak by a commercial energy dispersive X-ray fluorescence spectrometer (EDXRS). Compton scattering is an inelastic scattering of a photon by an electron. It results in a decrease of the X-ray energy, called the Compton Effect. The amount of energy change is called the Compton shift which is expressed as the Compton peak, near the main peak of the X-ray tube.

The intensity of the Compton peak is inversely proportional to the mass absorption coefficient ( $\mu$, $\mathrm{cm}^{2} / \mathrm{gr}$ ), Reynolds (1963). Taking into account that the mass absorption coefficient increases with the Atomic Number of a chemical element, it is clear that it is mainly defined by the mineral mater and therefore a relationship between the Compton Intensity and the amount of mineral mater is expected. In Figure 1 the peaks of $\mathrm{PdK} \alpha_{1}$ and its Compton peak of a Pd X-ray tube are given. Due to higher mass absorption coefficient of the mixed sulfide sample, the Compton intensity is lower than the $\mathrm{PdK} \alpha_{1}$ intensity.

On the contrary in lignite, because of the low mass absorption coefficient, the Compton intensity is higher than the $\mathrm{PdK} \alpha_{1}$ intensity. 


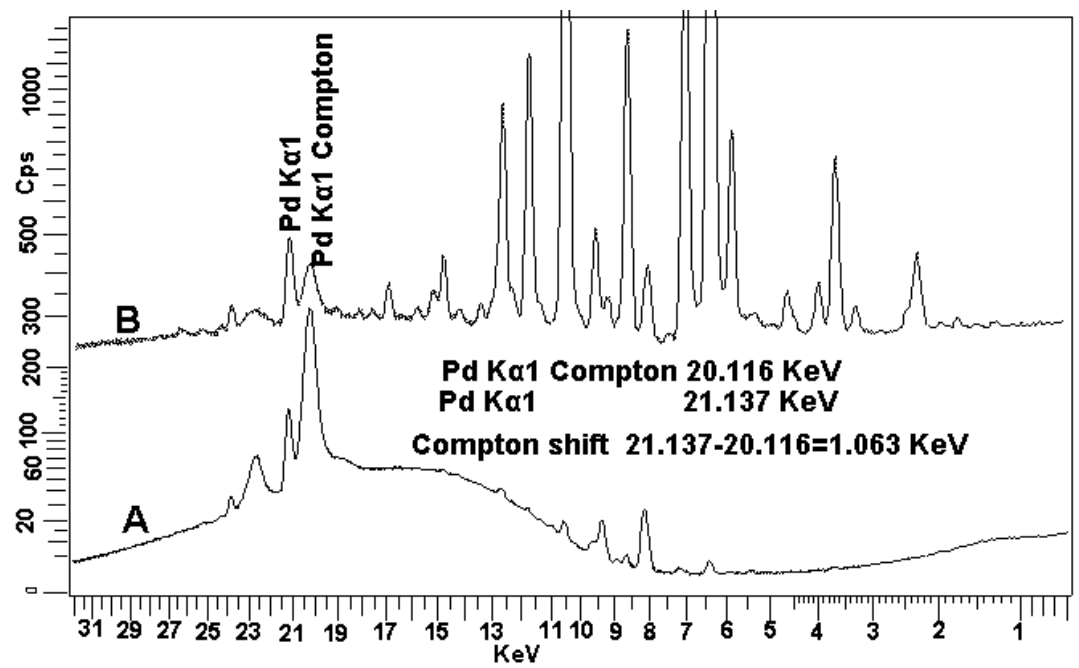

Figure 1 - X-spectra of a lignite (A) and a mixed sulfide ore (B) from a Pd X-ray tube.

\section{Sampling and Experimental Methods}

Five lignite samples with different content of mineral matter were selected from the Ptolemais basin, which is the main source of lignite fly ash produced in Greece. Each year approximately 10 millions tons of lignite fly ash are produced. Ptolemais lignite is of low quality, characterized by low calorific value and high mineral matter content (Koukouzas et al., 2006). The mineral matter and the calorific value of the analyzed samples are given in Table 1 and in Figure 2.

Table 1 - Mineral matter represented as ash wt-\%, and the calorific value of the analyzed samples (air-dried).

\begin{tabular}{|l|l|l|}
\hline Sample & Ash\% & $\begin{array}{l}\text { Cal. Value } \\
\text { (kJ/Kg }\end{array}$ \\
\hline Sector 6_1 & 17.28 & 4491 \\
\hline Sector 6_4 & 42.65 & 1547 \\
\hline Bunker 2 & 32.27 & 2947 \\
\hline Bunker 3 & 24.95 & 3775 \\
\hline Bunker 4 & 35.76 & 2584 \\
\hline
\end{tabular}

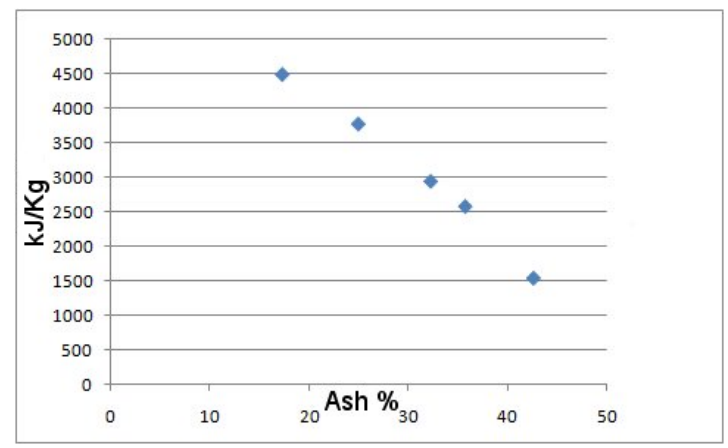

Figure 2 - Ash versus calorific value of the analyzed samples.

$\underline{\text { XLVII, No } 3-1647}$ 
LTA was applied to isolate the mineral matter of the lignite samples. An energy dispersive X-ray fluorescence spectrometer (EDXRS), type S2 RANGER, BRUKER Company (Germany) was used with Pd X-ray tube. The operating conditions, for the X-ray tube, were $40 \mathrm{KV}$, high voltage and $250 \mu \mathrm{A}$.

The lignite samples were air dried and grinded to $-60 \mu \mathrm{m}$ and pressed to tablets of $40 \mathrm{~mm}$ diameter. The crystalline phase analysis of the crystalline matter, after the LTA, was carried out on a Bruker D8 Advance Diffractometer, using Ni-filtered $\mathrm{Cu} \mathrm{K} \alpha$ radiation $(35 \mathrm{kV}, 35 \mathrm{~mA})$ with a Lynx Eye strip silicon detector. Data were collected from $3^{\circ}$ to $70^{\circ} 2 \theta$ with a step size of $0.019^{\circ}$ and a count time of $1 \mathrm{sec}$ per strip step. The diffractograms were qualitatively interpreted using the software Diffrac Plus from Bruker and the Powder Diffraction File (PDF). The quantitative analysis was performed by the Rietveld method, using the TOPAS software from BRUKER. In Table 2 the mineralogical composition of the mineral matter of the analyzed samples is given. A typical X-ray diffractogram is given in Figure 3.

Table 2 - Mineralogical composition of the analyzed samples after Low Temperature Ashing.

\begin{tabular}{|l|l|l|l|l|l|}
\hline Sample & $\begin{array}{l}\text { Aragonite } \\
\%\end{array}$ & $\begin{array}{l}\text { Calcite } \\
\%\end{array}$ & $\begin{array}{l}\text { Illite } \\
\%\end{array}$ & $\begin{array}{c}\text { Pyrite } \\
\%\end{array}$ & $\begin{array}{l}\text { Quartz } \\
\%\end{array}$ \\
\hline $\begin{array}{l}\text { Lignite 1 } \\
\text { LTA }\end{array}$ & 5.8 & 91.1 & 1 & 0.4 & 1.7 \\
\hline $\begin{array}{l}\text { Bunker 3 } \\
\text { LTA }\end{array}$ & 8.3 & 84.9 & 3 & 0.2 & 3.6 \\
\hline $\begin{array}{l}\text { Bunker 4 } \\
\text { LTA }\end{array}$ & 7.6 & 87 & 2.5 & 0.3 & 2.5 \\
\hline $\begin{array}{l}\text { Bunker 2 } \\
\text { LTA }\end{array}$ & 7.6 & 88.8 & 2.5 & 0.2 & 0.9 \\
\hline $\begin{array}{l}\text { Lignite } 4 \\
\text { LTA }\end{array}$ & 2.4 & 96.6 & 0.5 & 0 & 0.5 \\
\hline
\end{tabular}

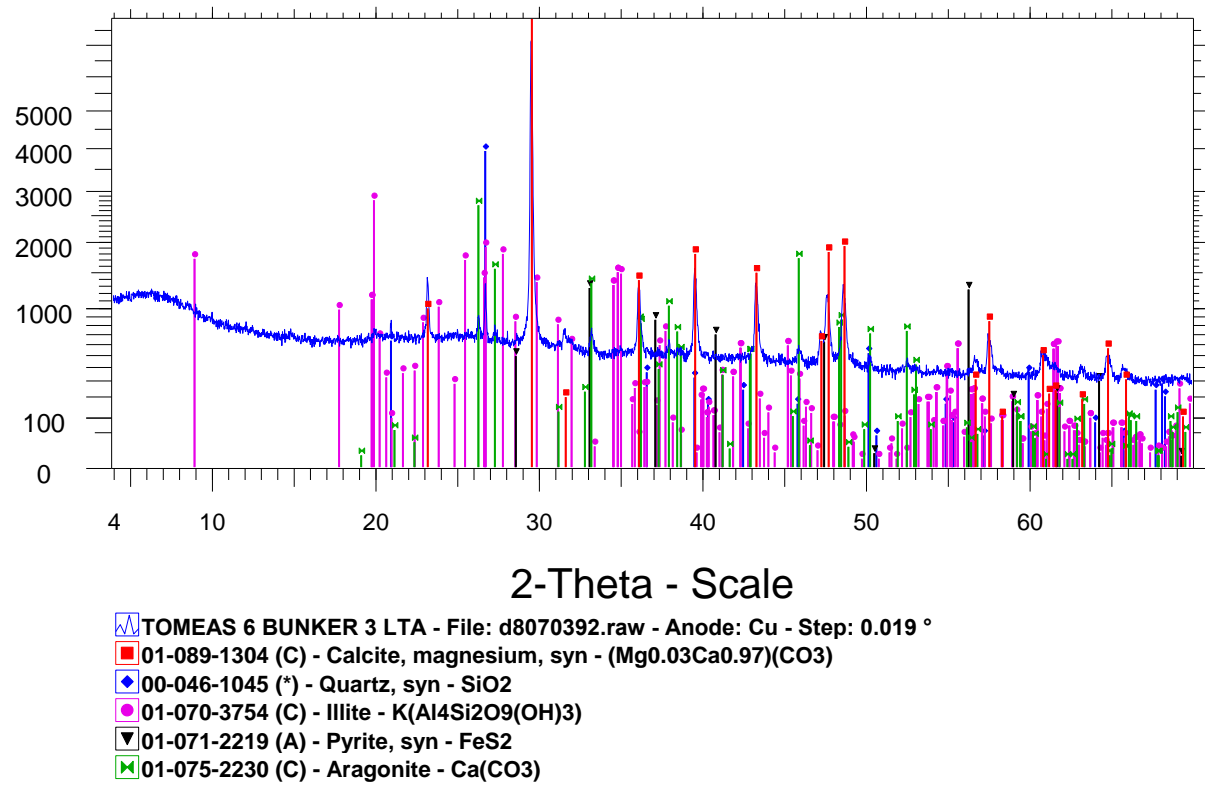

TOMEAS 6 BUNKER 3 LTA

Figure 3 - X-Ray diffractogram after Low Temperature Ashing (LTA).

XLVII, No $3-1648$ 
As mentioned before, the Compton peak intensity is reversely proportional to the mass absorption coefficient. To test this, synthetic standards were prepared with a xylite free of mineral matter (woody remnants) as matrix (Table 3).

The mass absorption coefficient was calculated for the energy of the $\mathrm{Pd} \mathrm{K} \alpha \mathrm{Peak}(21.137 \mathrm{KeV} \rightarrow \lambda$ $=0.5854 \AA$ ) according to the formula :

$\mu_{\lambda}=\sum_{\mathrm{i}=1}^{\mathrm{n}} \mu_{\lambda_{\mathrm{i}}} \times \mathrm{C}_{\mathrm{i}}$, where $\mu_{\lambda \mathrm{i}}$ is the $\mu_{\lambda}$ for the compound $\mathrm{i}$ and $\mathrm{C}_{\mathrm{i}}$ its concentration.

In Figure 4 the relation between concentration of mineral matter and $\mu$ of the standard samples is presented. It is expected, that the amount of $\mathrm{CaCO}_{3}$ in the analyzed lignite samples determines the value of $\mu$, since calcite is the main mineral. Figure 5 presents the relation between mineral matter of the synthetic samples and the Compton intensity. To avoid intensity shifts and instrumental recalibration, in Figure 6 the Ratio Compton Intensity to PdK $\alpha$ intensity is given, since this ratio is a constant number and independent from instrumental recalibration. According to these diagrams a clear relation is recognized between Compton intensity and mineral matter.

Table 3 - Bulk composition of synthetic standards using xylite as matrix.

\begin{tabular}{|l|l|l|l|l|}
\hline $\begin{array}{l}\text { Compound } \\
\text { Standard }\end{array}$ & K & L & M & N \\
\hline $\mathrm{SiO}_{2} \%$ & 20.96 & 15.72 & 10.48 & 5.24 \\
\hline $\mathrm{Al}_{2} \mathrm{O}_{3} \%$ & 1.61 & 1.21 & 0.81 & 0.40 \\
\hline $\mathrm{CaCO}_{3} \%$ & 11.52 & 8.64 & 5.76 & 2.88 \\
\hline $\mathrm{CaSO}_{4} \%$ & 1.1 & 0.82 & 0.55 & 0.27 \\
\hline $\mathrm{Fe}_{2} \mathrm{O}_{3} \%$ & 1.61 & 1.21 & 0.81 & 0.40 \\
\hline $\mathrm{MgO} \%$ & 0.64 & 0.48 & 0.32 & 0.16 \\
\hline $\mathrm{KCl} \%$ & 2.55 & 1.91 & 1.27 & 0.64 \\
\hline $\mathrm{Xylite} \%$ & 60 & 70 & 80 & 90 \\
\hline $\mathrm{Sum}$ & 100 & 100 & 100 & 100 \\
\hline$\mu\left(\mathrm{cm}^{2} / \mathrm{gr}\right)$ & 1.588 & 1.243 & 0.898 & 0.554 \\
\hline $1 / \mu\left(\mathrm{gr} / \mathrm{cm}^{2}\right)$ & 0.629 & 0.804 & 1.113 & 1.806 \\
\hline
\end{tabular}

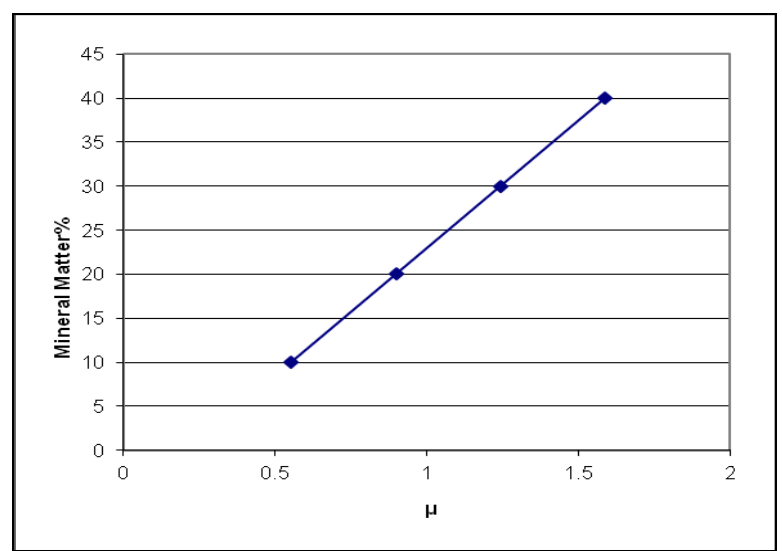

Figure 4 - Relation between mass absorption coefficient and mineral matter of the synthetic standards.

The same measurements were performed on the lignite samples. Again we observe a clear relation between Compton intensity and mineral matter content, expressed as ash \% (from table 1) 
(Figures 7 and 8). Therefore the lignite ash content can be determined easily by the measurement of the Compton Peak intensity by X-ray fluorescence.

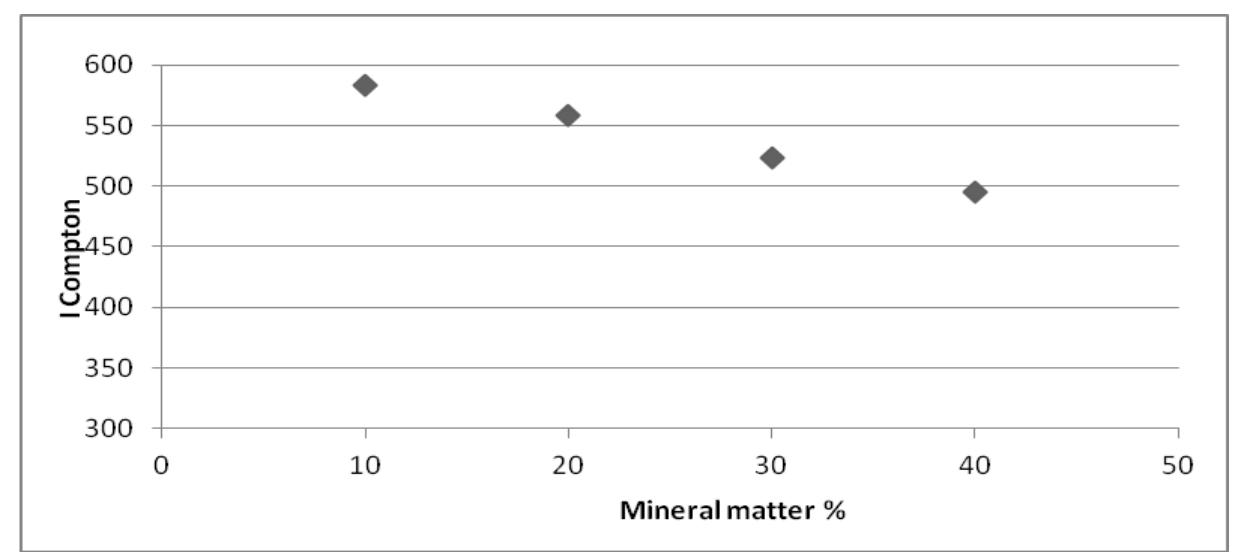

Figure 5 - Relation of mineral matter content and Compton Peak Intensity in synthetic samples.

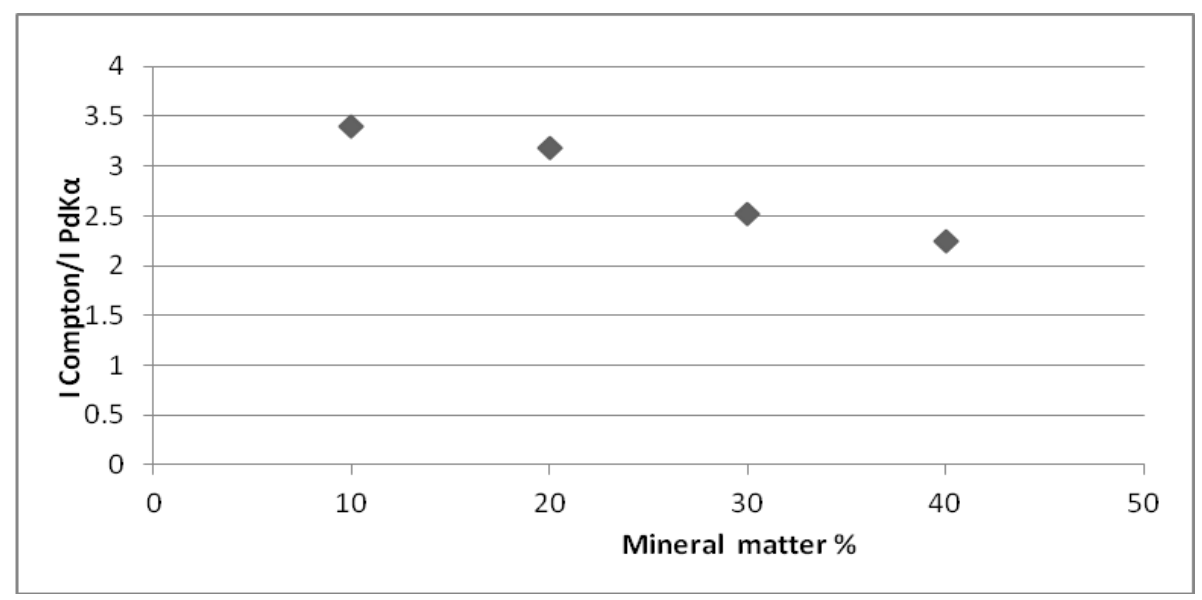

Figure 6 - Relation of mineral matter content and Ratio of the Compton Peak/PdKa Intensity in synthetic samples.

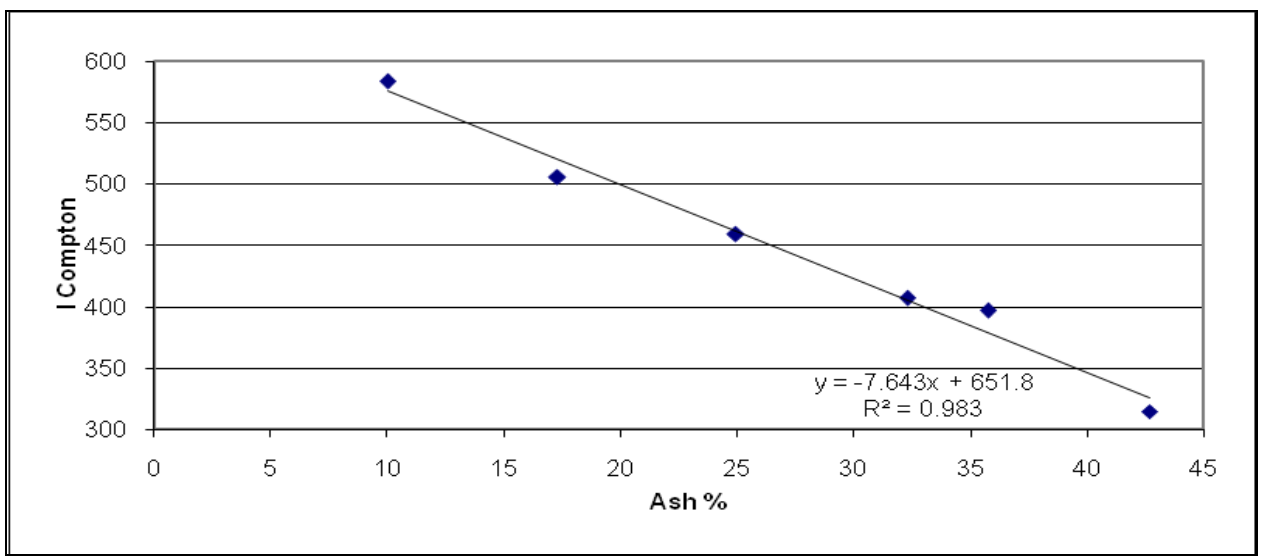

Figure 7 - Relation of ash content in lignite and the Compton Peak Intensity.

$\underline{\text { XLVII, No } 3-1650}$ 


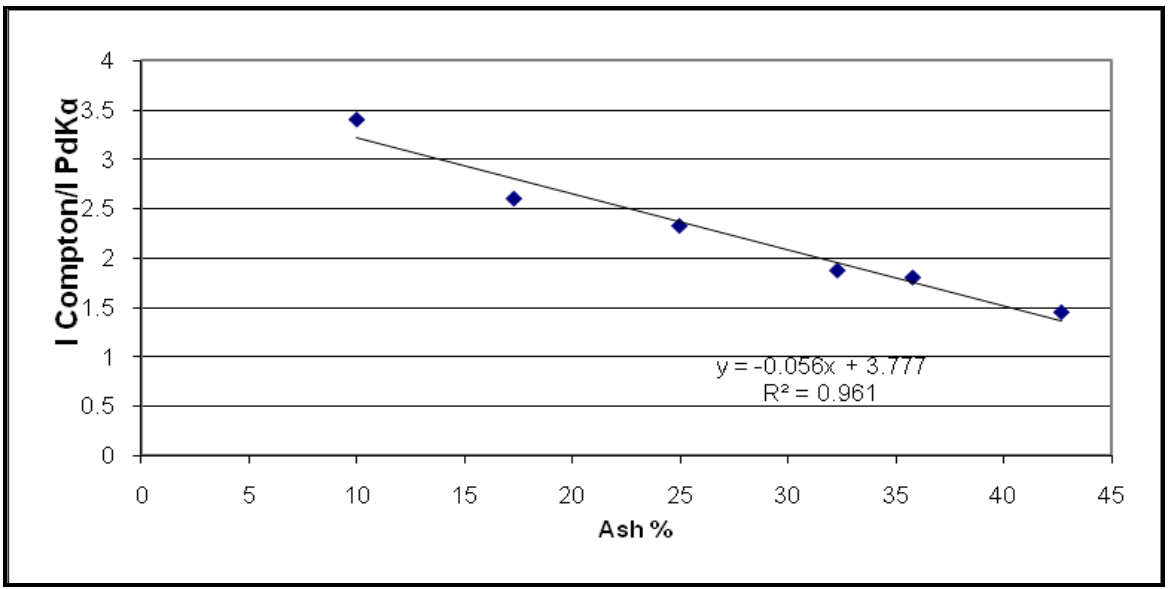

Figure 8 - Relation of ash content in lignite and Ratio of the Compton Peak/PdKa Intensity.

\section{Discussion and Conclusion}

The mineral matter content in lignite can be easily determined by the use of X-ray fluorescence spectroscopy and the Compton peak intensity of the X-ray tube. This can be done by a calibration curve with mineral matter $\%$ or ash $\%$, of known lignite samples versus Compton peak intensity. Calibrated samples and unknown lignite samples must have, qualitatively, the same mineralogical composition, regarding mineral matter. This is in most cases given for a certain lignite layer, as in the analyzed lignite samples, with calcite as the main mineral. This is important because the total value of mass absorption coefficient of a lignite sample can have the same value, theoretically, by different quantitative combination of the minerals in mineral matter.

\section{References}

ASTM D3174-12 Standard Test Method for Ash in the Analysis Sample of Coal.

Australian Standards 2000. Higher rank coal mineral matter and water of constitution. Australian Standard 1038, Part 22, 20pp.

Colin R. 2002. Analysis and significance of mineral matter in coal seams, International Journal of Coal Geology, 50, 135-168.

Finkelman R.B. 1994. Abundance, source and mode of occurrence of inorganic constituents in coal, in: Kural, O. (ed.) Coal. Istanbul Technical University, Istanbul, pp. 115-125.

Gary M., McAfee R. and Wolf C.L. (Eds) 1972. Glossary of Geology, American Geological Institute, Washington, DC, $805 \mathrm{pp}$.

Gluskoter H.J. 1965. Electronic low temperature ashing of bituminous coal. Fuel, 44, 285-291.

Harvey R.D., Ruch R.R. 1986. Mineral matter in Illinois and other US coals, in. Vores, K.S. (ed.) Mineral Matter in coal Ash and coal. American Chemical Society Symposium Series 301, pp 10-40.

Koukouzas N., Zeng R., Perdikatsis V., Xu W. and Kakaras E. 2006. Mineralogy and geochemistry of Greek and Chinese coal fly ash, Fuel, 85, 2301-2309.

Ritz M. and Klika Z. 2010. Determination of minerals in coal by methods based on the recalculation of the bulk chemical analyses, Acta Geodyn. Geomater., Vol. 7, No. 4 (160), 453-460.

Reynolds R.C. 1963. Matrix corrections in trace element analysis by X-ray Fluorescence: Estimation of mass absorption coefficient by Compton scattering, American Mineralogist, 48, 1133-1143.

Tickner J. and Roach G. 2004. Characterization of coal and minerals using Compton profile analysis, Nuclear Instruments and Methods in Physics Research B 213, 507-510.

XLVII, No $3-1651$ 